Research Article

\section{Asthma and pregnancy prevalence in a developing country and their mortality outcomes}

\author{
Raul Aguilar ${ }^{1 *}$, Jorge Martinez², Edgar Turcios ${ }^{3}$ and Victor \\ Castro ${ }^{4}$ \\ ${ }^{1}$ Pulmonologist School of Medicine. University of El Salvador, Final Calle Arce/25 Ave Sur, San \\ Salvador, El Salvador \\ ${ }^{2}$ Chief Epidemiology Officer (Retired), Primero de Mayo Hospital, Calle Ruben Dario/23 Ave Sur, \\ San Salvador, El Salvador \\ ${ }^{3}$ Obstetrician Gynecologist, Chief ICU, Primero de Mayo Hospital, Calle Ruben Dario/23 Ave Sur, \\ San Salvador, El Salvador \\ ${ }^{4}$ Pulmonologist, Hospital Nacional Rosales, Final Calle Arce/25 Ave Sur, San Salvador, El Salvador
}

\section{Abstract}

Background: Latin America has always had high maternal and infant mortality rates. However, the prevalence of asthma in pregnant patients and their outcomes are unknown.

We aimed at answering those questions in a developing country's maternity hospital.

Methods: Since January 2011, a cohort of 591 pregnant asthma patients was prospectively recruited for 60 consecutive months. Patients were followed up by a multidisciplinary team until delivery. They were divided into two groups: one of 186 smokers or morbidly obese patients and another of 405 nonobese nonsmokers. Outcomes of mothers and their babies were documented.

Results: Out of 57,031 deliveries, the overall estimated prevalence of 591 asthmatic pregnant patients was $1.03 \%$. When adjusted for age standardized prevalence, it turned to $9.2 \%$.

With 28 maternal deaths (49 per 100,000 live births). None of these women had asthma. There were also 413 deaths among newborns (7.24/1000 live births). One occurred in the smoker/ obese group (5.37/1000 live births) and two in the nonsmoker nonobese group (4.84/1000 live births). The prevalence of asthma during pregnancy seemed lower than in some affluent societies. Overall maternal mortality rates were similar to national figures; however, data on mothers' mortality with asthma were unexpectedly absent.

Conclusion: A multidisciplinary approach and the use of a low-cost inhaled steroid seemed to be the reasons for this. However, infant mortality rate remained high, which could be related to the risk of asthma itself. We believe there's a worldwide need for agreements on a standardized approach for asthma's epidemiological surveys, in order to make them comparable.

\section{More Information}

*Address for Correspondence: Raul Aguilar, Pulmonologist School of Medicine. University of El Salvador, Final Calle Arce/25 Ave Sur, San Salvador, El Salvador,

Email: detectiveprivado2@yahoo.ca

Submitted: August 21, 2021

Approved: September 04, 2021

Published: September 06, 2021

How to cite this article: Aguilar R, Martinez $\mathrm{J}$, Turcios E, Castro V. Asthma and pregnancy prevalence in a developing country and their mortality outcomes. J Pulmonol Respir Res. 2021; 5: 088-093.

DOI: 10.29328/journal.jprr.1001031

Copyright: @ 2021 Aguilar R, et al. This is an open access article distributed under the Creative Commons Attribution License, which permits unrestricted use, distribution, and reproduction in any medium, provided the original work is properly cited.

Keywords: Asthma; Pregnancy; Outcomes

\section{Check for updates}

OPEN ACCESS

\section{Introduction}

Latin America has high maternal mortality rates, from 15 (per 100,000 live births) in Uruguay to 206 in Bolivia, in 2015 [1]. Developed nations such as Spain or Canada had a maternal mortality rate of 5 in the same year [2] or 4.8 in 2011 [3], respectively. In Central America, Costa Rica has the lowest maternal mortality rate at 25, followed by El Salvador at 42 , and Nicaragua at 150 [1]. The same is true for infant mortality: 9 in Costa Rica and 19 in Nicaragua [1]. El Salvador's latest report shows a rate of 10.7 (per 1000 live births) in children less than 5 years old, 5.7 in babies less than 28 days old, and 4.3 in babies less than 7 days old [4], which is three times higher than in France and Germany [1].

When investigated using written standardized questionnaires, Latin America's self-reported symptom prevalence of chest wheezing over the past 12 months in teenagers aged 13-14 years rose from approximately $7 \%$ in Mexico to $25 \%$ in Peru [5]. Central America reported rates of asthma diagnosis in children of the same age, ranging from $15.2 \%$ in Nicaragua to $23 \%$ in Costa Rica and $24 \%$ in 
El Salvador [6]. In terms of asthma symptoms, these rates were lower than those in the UK (37\%), Australia (35\%), and Canada (31\%), but higher than those in Finland (14\%), Germany (13\%), France (12\%), and Belgium (12\%) [5]. While asthma prevalence in pregnant patients and their outcomes are well known in other countries and regions [7-11], we found only one Mexican case series of 296 patients recruited from June 1998 to May 1999 reporting a prevalence of $2.5 \%$ in pregnant teenagers [12].

Asthma, indicated by a history of physician diagnosis, is a valid definition for epidemiological studies $[13,14]$. However, such definition has also been addressed in different ways. Some obtain it as a self-reported diagnosis by patients themselves, when asked whether they have been told by a doctor they have asthma [14-16], from chart reviews [7], by answering a phone interview [17] or a questionnaire [18,19], or retrospectively from administrative data files $[9,11,20,21]$. It is known that most retrospective studies are subject to recall bias. In fact, we found that 15 out of 18 studies obtained their data in such a manner. Very few got it directly by physicians' diagnosis in prospectively recruited cohorts [15,22,23].

From the standpoint of infants, the most severe complication of pregnancy is fetal or neonatal death. However, many published surveys did not control for confounding factors known to increase fetal mortality risk, such as smoking or obesity $[11,15,20,21,24]$. In one study of 620 pregnant patients with respiratory symptoms, 132 were patients with asthma and at the same time smokers [25]. We did not find a study that intentionally controlled smoking as a risk factor. Obesity, meaning a body mass index (BMI) $>30$, in pregnancy has also been associated with an increased risk of asthma exacerbations [26]. In a Swedish study from a general population's birth registry of 805,275 women, morbid obesity $(\mathrm{BMI}>35)$ was found to be associated with an increased risk of stillbirths and early neonatal death [27]. Again, we were unable to find any study that specifically controlled obesity as a confounding factor in pregnant patients with asthma.

There are no recent Latin American reports on asthma and pregnancy prevalence and no reports on maternal or newborn mortalities to compare them to those of developed nations.

Accordingly, we estimated the prevalence and mortality rates in a cohort of pregnant women with asthma and their newborns in a low-income country with high maternal and high infant mortalities, while attempting to overcome the obstacles faced by other researchers, by controlling confounding factors for asthma itself, such as active and passive smoking, and those for infant mortality such as morbid obesity, in addition to collecting data in a prospective manner to decrease the chances of recall biases.

\section{Methods}

The Primero de Mayo Hospital is a 198-bed gynecology/ obstetrics referral institution. It takes care of about 250,000 pregnant and nonpregnant women living in San Salvador's area. Besides attending to normal pregnancies and deliveries, it also manages high-risk pathologies, and most prenatal outpatients are admitted only by referral from attending obstetricians in primary care settings. Once the hospital's obstetricians perform the initial screening for comorbidities, patients are sent to the corresponding specialist for prenatal follow-up, in this case, to the outpatient respiratory clinic. From the first working day in January until the last working day in December from 2011 to 2015 (5 years), a cohort was recruited by logging it in a prospective manner based on the following criteria: (1) chart record identification number; (2) pregnancy and asthma diagnosis with or without other comorbidities; (3) pre pregnancy BMI > 35, estimated by subtracting $1 \mathrm{~kg}$ for every month of gestational age; (4) fetal and neonatal outcomes followed up and recorded; (5) being a current active smoker or having smoked for at least 12 consecutive months over the previous 2 years; and (6) being a passive smoker either at home or at work for at least 12 consecutive months. Second-hand smoking is known to trigger asthma [28]. The following were the exclusion criteria: (1) lifelong exposure to cooking wood smoke at home or at work and (2) use of chronic oral or topical beta-blocker or ACE inhibitors.

Because of the study's characteristics, all patients' rights were granted and IRB permission was waved.

\section{Asthma diagnostic criteria}

Patients were recruited on every working day as they came to the respiratory clinic for appointments for 60 consecutive months.

Asthma was diagnosed according to the 2010 GINA guidelines:

1. Asking the patients if they had been told by a doctor that they had asthma, and if the answer was yes, they were asked if they still had on and off the presence of at least one of the following symptoms: wheeze, chest tightness, shortness of breath, or persistent or intermittent cough, all of which vary in time and intensity, followed by an examination focused on the upper airways, thorax, and skin [29] or

2. Improvement of symptoms described above after use of short-acting bronchodilators at the first office appointments or at follow-up visits

3. On clinical grounds (history, physical examination, and routine laboratory examinations and chest radiography, plus, when needed, fiber-optic laryngoscopy, spirometry, and plethysmography, except computerized tomography scan),

the following diagnosis were excluded: 
a) Vocal cord dysfunction

b) COPD

c) Bronchopulmonary Allergic Aspergillosis

d) Chronic sinusitis

e) Cystic fibrosis

f) Pneumonia

g) Heart failure

h) Idiopathic pulmonary hypertension

i) Tuberculosis

j) Vasculitis of the lungs

We did not exclude the following:

a) GERD, because it has been suggested to be less prevalent in pregnant patients with asthma than that in pregnant patients without asthma [30].

b) Eosinophilic Bronchitis, as it is very uncommon and its definitive diagnosis is made through bronchial biopsy, which we considered impractical for this study.

c) Alpha 1 antitrypsin deficiency, because of a lack of resources to make such diagnosis.

d) Hypereosinophilic obliterans bronchitis, as by the time this study was started, such a disease had not been described yet [31].

e) Whether they knew how to or not, all first-time patients were trained by one of the authors (RA) to use inhalers either directly or through a spacer. Short-acting beta agonists (salbutamol) were prescribed as needed, with inhaled corticosteroids (beclomethasone) to be used regularly. Because of literacy problems, a written management plan was not suitable for everyone; therefore, it was avoided. Patients were verbally educated about asthma, as well as the importance of sticking to the treatment plan and avoiding triggers. All patients had monthly follow-ups and underwent at least one spirometry test during the whole pregnancy. Further tests were requested when needed. Mostwomen had been diagnosed with asthma before becoming pregnant and had normal spirometry results. Twentyone (about 3.5\%) patients with exacerbation were identified during office appointments and had to be admitted for treatment with systemic steroids.

We aimed to meet four important aspects of asthma treatment: mother's close monitoring and education about her disease, trigger avoidance, and proper pharmacological treatment.

\section{Results}

The flowchart of deliveries and outcomes is shown in Figure 1. There were 57,031 deliveries managed at the hospital; 41,081 were pregnancies without comorbidities, and 15,950 pregnancies were associated comorbidities. Namely, about two-thirds had diabetes and/or high blood pressure and/or hypothyroid disease.

Out of those pregnant with comorbidities, there were 634 referred to the respiratory clinic, with at least one asthma associated symptom (episodic dyspnea, cough, wheezing or chest tightness).

Among them, we diagnosed 405 asthmatics non obese nonsmokers.

We also diagnosed 186 who were either obese and or second-hand smokers: 56 non obese second-hand smokers plus 93 obese second-hand smokers and 37 obese but with no exposure to second hand smoking, leading to a total of 591 pregnant patients with diagnosis of asthma.

Their ages were between 18 to 37 years old. All but two came to full term. No active smokers were pregnant. A total of

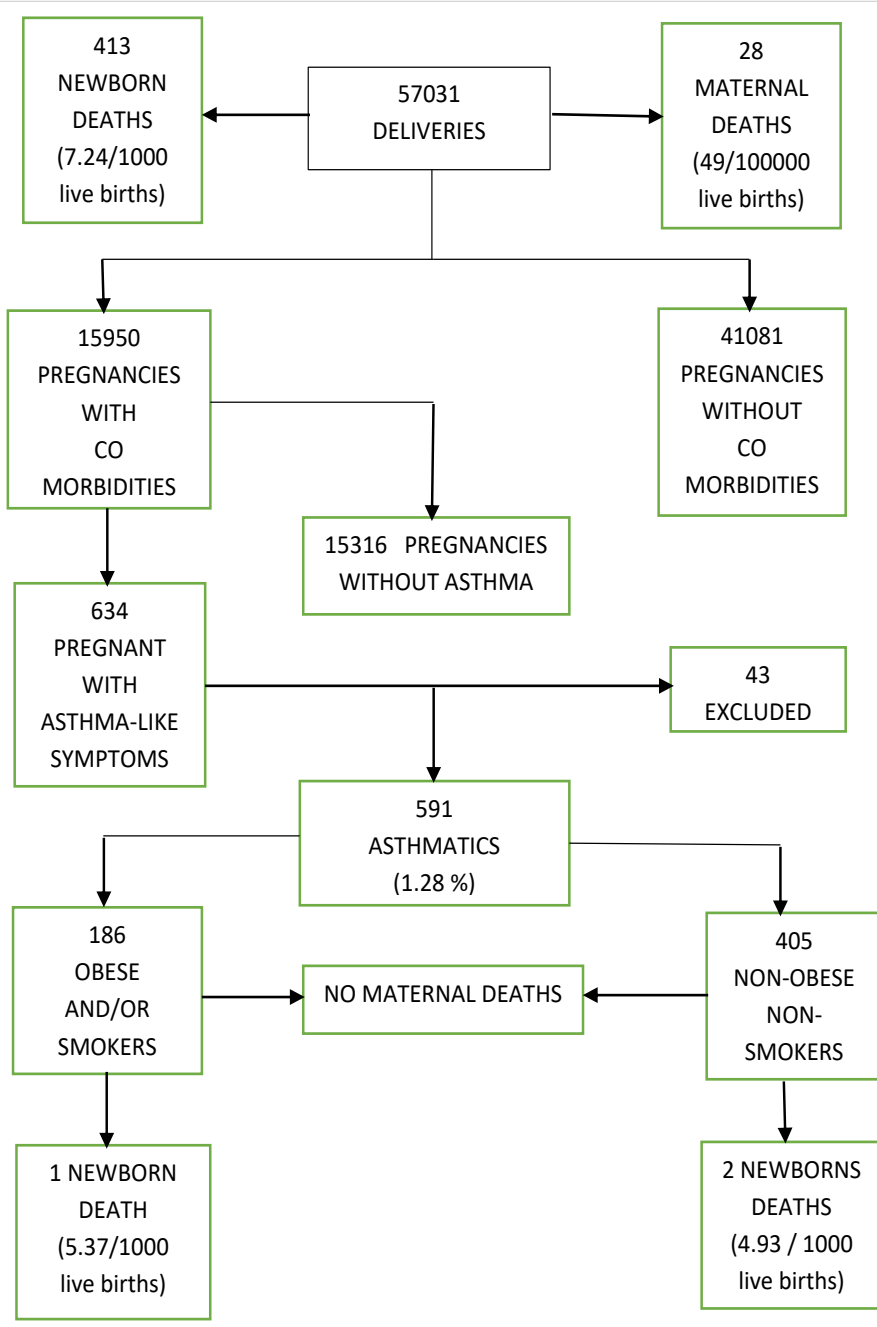

Figure 1: Deliveries and outcomes flowchart. 
43 patients were excluded, mostly because of other diagnosis such as acute bronchitis, pneumonia, tuberculosis, chronic sinusitis, heart failure, bronchopulmonary aspergillosis or idiopathic pulmonary hypertension. Nobody was on chronic antihypertensive treatment nor exposed to wood smoke for cooking. The estimated asthma prevalence for the total number of deliveries was $1.03 \%$. El Salvador's 2019 estimated population was $6,420,146$ people and the number for the 1837 years old women's segment was 1,181,654 people [32].

Accordingly, after calculating the respective crude rate, the estimated age standardized prevalence was $9.2 \%$. Among the 57,031 deliveries, there were 413 newborn deaths (7.25/100,000 live births). One occurred in a second-hand smoker and obese woman (5.37/1000 live births) due to prematurity, and two belonged to one nonobese nonsmoker mother. They were twin boys who died in 2013 because of prematurity ( 4.93 per 1000 live births). Twenty-eight maternal deaths occurred during the investigation period, equivalent to 49 per 100,000 live births. None of these patients had asthma.

\section{Discussion}

We attempted to overcome the limitations of other studies by implementing prospective clinical data gathering and controlling for confounding factors such as smoking and obesity. A 2014 survey showed that $2 \%$ of women and $17 \%$ of men were active smokers in El Salvador. Therefore, this is probably the main reason why there were no active female smokers in the cohort, but instead, a rather unusual number of second-hand smokers [33]. Conversely, according to local figures, up to approximately $12 \%$ of school girls were obese, which seems to also apply to pregnant adult women [34]. Asthma is episodic and variable, and its diagnosis can be difficult due to different diseases with similar presentations and because there is no single measure to provide definite proof of it. In addition, spirometry has been questioned as being too variable when it comes to defining airflow obstruction. It has been pointed out that the fixed cutoff points of FEV1/ FVC ratios may misidentify airflow obstruction in adults, with an overestimation of the value of 0.80 and underestimation of the value of 0.70 [35]. The diagnosis of asthma depends more on physicians' correlation of patient history, physical examination, and pulmonary function tests [36]. Because of its episodic nature, some women diagnosed with asthma may not be symptomatic during pregnancy and as there are no definite diagnostic criteria, a number of undiagnosed individuals may have symptoms during pregnancy. Thus, distinctions made only on the basis of asthma diagnosis can lead to misclassification [37]. Over or underdiagnosis is a potential event $[17,38]$. For example, an earlier Canadian study found that 129 out of 206 patients diagnosed with asthma did not show airway responsiveness on methacholine test [39].

Asthma appears to be more common in wealthy nations [19]. Within countries, evidence for this association is conflicting [40,41]. More recent data support the fact that asthma is associated with low social and economic status, regardless of the country where the person lives [42]. One reason for these differences may be the diagnostic methodology. In this context, relying on symptoms such as cough and wheezing could be misleading. Those with better access to health care get diagnosed and treated earlier. For example, in the USA, Black and Hispanic women have an increased perinatal risk when compared to white women with the same characteristics $[14,15,17,43]$. Some studies have reported higher asthma prevalence in the general population than in pregnant women. In the UK, USA, and Australia, estimations of asthma prevalence and pregnancy range from approximately $8 \%$ to $12 \%([8,44,45]$. This is more than ten times the prevalence in our findings. We suspect it is due to methodological discrepancies.

We think that our estimates are valid, considering that the population from which the sample was taken is about 250,000 women. The impact of asthma associated with pregnancy on fetal and newborn welfare has never been investigated in a developing country with high maternal and infant mortalities. While we acknowledge this study's main weakness, is the rather small sample size, maternal and newborn mortalities were as expected. However, the deaths of mothers with asthma were surprisingly absent, considering the high prevalence of maternal mortality in the population as a whole. Close prenatal follow-up through a multidisciplinary approach and a low-cost inhaled steroid appear both to be the main reasons. However, to date there's not enough information about what would be the best pharmacological and non-pharmacological management of pregnant asthmatic patients [46,47].

Unfortunately, infant mortality does not change according to national rates [4]. As for deaths of premature babies, we thought the risk seemed independent of the use of corticoids or other factors $([14,15,22]$.

Finally, asthma and pregnancy prevalence seemed lower than that in some affluent societies. We believe there is a worldwide need for agreements on a standardized approach for asthma's epidemiological surveys in order to make them comparable.

This research did not receive any specific grant from funding agencies in the public, commercial, or not-for-profit sectors.

\section{References}

1. WHO. Global Health Observatory. 2017

2. 2017. Worldbank.org/indicators

3. Statistic Canada. 2011. www.statcan.gc.ca/

4. MINSAL 2015. www.salud.gob.sv

5. ISAAC Steering Committee. Worldwide variation in prevalence of symptoms of asthma, allergic rhino conjunctivitis and atopic eczema: ISAAC Lancet. 1998; 351: 1225-1232.

PubMed: https://pubmed.ncbi.nlm.nih.gov/9643741/ 
6. GAN.2017. www.globalAsthmaNetwork.org

7. Sorensen TK, Dempsey JC, Xiao R, Ihunnaya F, Luthy D, et al. Maternal asthma and risk of pre term delivery. Ann Epidemiol. 2003; 13: 267-272. PubMed: https://pubmed.ncbi.nlm.nih.gov/12684193/

8. Murphy VE, Gibson PG. Asthma and pregnancy. Clin Chest Med. 2011; 32: 93-110.

PubMed: https://pubmed.ncbi.nlm.nih.gov/21277452/

9. Liu S, Wen SW, Demissie K, Marcoux S, Kramer MS. Maternal asthma and pregnancy outcomes: a retrospective cohort study. Am J Obstet Gynecol. 2001; 184: 90-96.

PubMed: https://pubmed.ncbi.nlm.nih.gov/11174486/

10. Sheiner E, Mazor M, Levy A, Wiznitzer A, Bashiri A. Pregnancy outcome of asthmatic patients: a population-based study. J Matern Fetal Neonatal Med. 2005; 18: 237-240.

PubMed: https://pubmed.ncbi.nlm.nih.gov/16318973/

11. Tata LJ, Lewis SA, McKeever TM, Smith CJP, Doyle P, et al. Effect of maternal asthma, exacerbations and asthma medication use on congenital malformations in offspring: a UK population-based study. Thorax. 2008; 63: 981-987.

PubMed: https://pubmed.ncbi.nIm.nih.gov/18678701/

12. Pereira LS, Plascencia JL, Ahued R, García Benítez C, Priego Iturralde Rosas $\mathrm{P}$, et al. Maternal morbidity in adolescent pregnancy. Ginecol Obstet Mex. 2002; 70: 270-274.

PubMed: https://pubmed.ncbi.nlm.nih.gov/12148468/

13. Tata L, Lewis SA, McKeever TM, Smith CJP, Doyle P, et al. A comprehensive analysis of adverse obstetric and pediatric complications in women with asthma. Am J Respir Crit Care Med. 2007; 175: 991-997. PubMed: https://pubmed.ncbi.nlm.nih.gov/17272783/

14. Dombrowski MP, Schatz M, Wise R, Momirova V, Landon M, et al. Asthma during pregnancy. Obstet Gynecol. 2004; 103: 5-12.

PubMed: https://pubmed.ncbi.nlm.nih.gov/14704237/

15. Bracken MB, Triche EW, Belanger K, Saftlas A, Beckett WS, et al. Asthma symptoms, severity, and drug therapy: a prospective study of effects on 2205 pregnancies. Obstet Gynecol. 2003; 102: 739-752. PubMed: https://pubmed.ncbi.nlm.nih.gov/14551004/

16. Bakhireva LN, Lyons Jones K, Schatz M, Johnson D, Chambers CD. Asthma medication use in pregnancy and fetal growth. J Aller Clin Immunol. 2005; 116: 503-509.

PubMed: https://pubmed.ncbi.nIm.nih.gov/16159616/

17. Kwon HL, Triche EW, Belanger K, Bracken MB. The epidemiology of asthma during pregnancy: prevalence, diagnosis and symptoms. Immunol Allergy Clin N Am. 2006; 26: 29-62.

PubMed: https://pubmed.ncbi.nlm.nih.gov/16443142/

18. Hancox RJ, Milne BJ, Taylor DR, Greene JM, Cowan JO, et al. Relationship between socioeconomic status and asthma: a longitudinal cohort study. Thorax. 2004; 59: 376-380.

PubMed: https://pubmed.ncbi.nlm.nih.gov/15115861/

19. Mihrshahi S, Belousova E, Marks GB, Peat JK. Pregnancy and birth outcomes in families with asthma. J Asthma. 2003; 40: 181-187. PubMed: https://pubmed.ncbi.nIm.nih.gov/12765320/

20. Blais L, Beauchesne MF, Rey E, Malo JL, Forget A. Use of inhaled corticosteroids during the first trimester of pregnancy and the risk of congenital malformation among women with asthma. Thorax. 2007; 62: 320-328.

PubMed: https://pubmed.ncbi.nlm.nih.gov/17121872/

21. Breton MC, Beauchesne MF, Lemiere C, Rey E, Forget A, et al. Risk of perinatal mortality associated with asthma during pregnancy. Thorax. 2009; 64: 101-106.

PubMed: https://pubmed.ncbi.nlm.nih.gov/19008298/

22. Bakhireva M, Shatz M, Lyon Jones K, Chambers CD. Asthma control during pregnancy and the risk of pre term delivery or impaired fetal growth. Ann Allergy Asthma Immunol. 2008; 101: 137-143. PubMed: https://pubmed.ncbi.nlm.nih.gov/18727468/
23. Schatz M, Dombrowski M, Wise R, Momirova V, Landon M, et al. The relationship of asthma medication use to perinatal outcomes. J Allergy Clin Immunol. 2004; 113: 1040-1045.

PubMed: https://pubmed.ncbi.nlm.nih.gov/15208581/

24. Minerbi-Codisha I, Fraser D, Avnun L, Glezerman M, Heimer D. Influence of asthma in pregnancy on labor and the newborn. Respiration. 1998; 65: 130-135.

PubMed: https://pubmed.ncbi.nlm.nih.gov/9580925/

25. Belanger K, Hellenbrand ME, Holford TR, Bracken M. Effect of asthma on maternal symptoms and medication use. Obstet Gynecol 2010; 115: 559-567.

PubMed: https://pubmed.ncbi.nIm.nih.gov/20177287/

26. Hendler I, Schatz M, Momirova V, Wise R, Landon M, et al. Association of obesity with pulmonary and non pulmonary complications of pregnancy in asthmatic women. Obstet Gynecol. 2006; 108: 77-82. PubMed: https://pubmed.ncbi.nlm.nih.gov/16816059/

27. Cedegren MI. Maternal morbid obesity and the risk of adverse maternal outcome. Obstet Gynecol. 2004; 103: 219-224.

PubMed: https://pubmed.ncbi.nlm.nih.gov/14754687/

28. Eisner MD, Yelin EH, Katz PP, Earnest G, Blanc PD. Exposure to indoor combustion and adult asthma outcomes: environmental tobacco smoke, gas stoves, and woodsmoke. Thorax. 2002: 57: 973-978. PubMed: https://pubmed.ncbi.nlm.nih.gov/12403881/

29. National Asthma Education and Prevention Program. Expert panel report (EPR3): guidelines for the diagnosis and management of asthma. Summary report 2007. J Allergy Clin Immunol. 2007; 120: S94-138. PubMed: https://pubmed.ncbi.nlm.nih.gov/17983880/

30. Bidad K, Zendehdel N, Heidarnazhad H, Pourpak Z, Moin M. Gastroesophagial reflux disease and asthma in pregnant women. Eur Respir J. 2011; 38: 527

31. Cordier JF, Cottin V, Khouatra C, Revel D, Proust C, et al Hypereosinophilic obliterative bronchiolitis: a distinct, unrecognized syndrome. Eur Respir J. 2013; 41: 1126-1134.

PubMed: https://pubmed.ncbi.nlm.nih.gov/23258778/

\section{2021. www.populationpyramid.net}

33. Ministry of Health. Investment case for tobacco control in El Salvador 2020. www.undp.org.

34. Perez W, Garces A, de Marquez AD, Merino G, Siu C. Overweight and obesity of school age children in El Salvador according to two international systems: a population based multilevel and spatial analysis. BMC Public Health. 2020; 20: 687-697.

35. Cerveri I, Corisco AG, Accordini S, Cervio G, Ansaldo E, et al. What defines airflow obstruction in asthma? Eur Respir J. 2009; 34: 568-573. PubMed: https://pubmed.ncbi.nlm.nih.gov/19720808/

36. Gjevre JA, Hurst TS, Cockcroft DW. The American Thoracic Society spirometric criteria alone is inadequate for asthma diagnosis. Can Respir J. 2006; 13: 433-437.

PubMed: https://pubmed.ncbi.nlm.nih.gov/17149462/

37. Triche EW, Saftlas AF, Belanger K, Leaderer BP, Bracken MB. Association of asthma diagnosis, severity, symptoms, and treatment with risk of preeclampsia. Obstet Gynecol. 2004; 104: 585-593. PubMed: https://pubmed.ncbi.nIm.nih.gov/15339773/

38. Linden Smith J, Morrison D, Deveau C, Hernandez P. Overdiagnosis of asthma in the community. Can Respir J. 2004; 11: 111-116. PubMed: https://pubmed.ncbi.nlm.nih.gov/15045041/

39. Joyce DP, Chapman KR, Kesten S. Prior diagnosis and treatment of patients with normal results of methacholine challenge test and unexplained respiratory symptoms. Chest. 1996; 109: 697-701. PubMed: https://pubmed.ncbi.nlm.nih.gov/8617078/

40. Mielk A, Reitmer P, Wjst M. Severity of childhood asthma by socioeconomic status. Int J Epidemiol. 1996; 25: 388-393. PubMed: https://pubmed.ncbi.nlm.nih.gov/9119565/ 
41. Rona RJ. Asthma and poverty. Thorax. 2000; 55: 239-244. PubMed: https://pubmed.ncbi.nlm.nih.gov/10679545/

42. Uphoff E, Cabieses B, Pinart M, Valdés M, Antó JM, et al. A systematic review of socioeconomic position in relation to asthma and allergy diseases. Eur Respir J. 2015; 46: 364-374.

PubMed: https://pubmed.ncbi.nIm.nih.gov/25537562/

43. Carrol KN, Griffin MR, Gebretsadik T, Shintani A, Hartert TV. Racia differences in asthma morbidity during pregnancy. Obstet Gynecol. 2005; 106: 66-72.

PubMed: https://pubmed.ncbi.nlm.nih.gov/15994619/

44. Clark JM, Hulme E, Devendrakumar V, Turner MA, Baker PN, et al. Effect of maternal asthma on birth weight and neonatal outcome in a British inner-city population. Pediatr Perinat Epidemiol. 2007; 21: 154-162. PubMed: https://pubmed.ncbi.nlm.nih.gov/17302644/

45. Kwon HL, Belanger K, Bracken MB. Asthma prevalence among pregnant and child bearing aged women in the United States. Estimates from national health surveys. Ann Epidemiol. 2003; 13: 317-324. PubMed: https://pubmed.ncbi.nlm.nih.gov/12821270/

46. Namazy JA, Schatz M. Contemporary management and treatment strategiesforasthmaduring pregnancy. ExpertRevRespirMed.2021:1-9. PubMed: https://pubmed.ncbi.nlm.nih.gov/34058955/

47. Cusack RP, Gauvreaus GM. Pharmacotherapeutic management of asthma in pregnancy and the effect of sex hormones. Expert Opin Pharmacother. 2021: 22: 339-349.

PubMed: https://pubmed.ncbi.nlm.nih.gov/32988248/ 